\title{
An Optimal Approach of Adaptive Neuro -Fuzzy Inference System to Predict the Roof Ductility Demand of EBFs Subjected to Near-Fault Pulse-Like Ground Motions
}

\author{
Seyed Abdonnabi Razavi \\ Department of Civil Engineering, \\ Islamic Azad University, Ahvaz Branch, Ahvaz, Iran. \\ E-mail: razavi@iauabadan.ac.ir \\ Navid Siahpolo \\ Department of Civil Engineering, \\ ACECR Institute for Higher Education, Khouzestan Branch, Ahvaz, Iran. \\ Corresponding author: siahpolo@acecr.ac.ir, n.siahpolo@gmail.com \\ Mehdi Mahdavi Adeli \\ Department of Civil Engineering, \\ Islamic Azad University, Ahvaz Branch, Ahvaz, Iran. \\ E-mail: mehmahad@yahoo.com
}

(Received June 16, 2020; Accepted August 19, 2020)

\begin{abstract}
Careful estimation of global ductility will certainly lead to greater accuracy in the design of structural members. In this paper, a new and optimal intelligent model is proposed to predict the roof ductility $\left(\mu_{R}\right)$ of EBF steel frames exposed to the near-fault pulse-like earthquakes, using the Adaptive Neuro-Fuzzy Inference System (ANFIS). To achieve this goal, a databank consisting of 12960 data is created. To establish different geometrical properties of models, 3-,6-, 9-, 12-, 15, 20-stories, steel EBF frames are considered with 3 different types of link beam, column stiffness, and brace slenderness. All models are analysed to reach 4 different performance levels using nonlinear time history under 20 near-fault earthquakes. About 6769 data are applied as ANFIS training data. Subtractive clustering and Fuzzy C-Mean clustering (FCM) methods are applied to generate the purposed model. The results show that FCM provides more accurate outcomes. Moreover, to validate the model, 2257 data are applied (as test data) in order to calculate the correlation coefficient $(R)$ and mean squared error (MSE) between the predicted values of $\left(\mu_{R}\right)$ and the real values. The results of correlation analysis show the high accuracy of the proposed intelligent model.
\end{abstract}

Keywords- Adaptive neuro-fuzzy inference system, Global ductility, Performance levels, EBF frames, Intelligent model.

\section{Introduction}

The ductility concept (demand and capacity) is well-defined in various performance levels with developing numerical techniques and the tendency of seismic codes to apply ductile structures. The primary classification provides three ductility types, the global, inter-story, and element ductility (Siahpolo et al., 2016). The global ductility, $\mu_{R}$, involves various engineering demand parameters (EDP), including a plastic rotation at member ends, story-drift, and roof displacement (Xiang et al., 2018). The structural seismic performance can be evaluated by the combination of the EDP and the intensity measure (IM) of ground motions (Xiang et al., 2018). A structure nonlinear seismic response, in the ductility-based methods, can be defined with a rather good accuracy (TenaColunga, 2001). The IM of ground motions, in conventional ductility-based methods, is reflected by the structural strength reduction factor, $R$ ( or $q$ ), basically measuring the structural strength to 
International Journal of Mathematical, Engineering and Management Sciences

Vol. 5, No. 6, 1516-1537, 2020

https://doi.org/10.33889/IJMEMS.2020.5.6.112

the seismic demand (Xiang et al., 2018). The weaker structure means the stronger the earthquake input necessitating the larger EDP or $\mu_{R}$ (Fanaie and Ezzatshoar, 2014; Siddique et al., 2014; Cai et al., 2016; Lu et al., 2016). In the ductility-based methods for seismic design or evaluation, one of the main issues is to develop an appropriate association between the structural nonlinear response (damage status) and the earthquake input intensity, i.e., the relationship of $R-\mu$ (Lee et al., 1999; Chakraborti and Gupta, 2005; Zhao and Tong, 2010; Avilés and Pérez-Rocha, 2011).

Researchers have recognized that seismic ground motions nearby to an active fault could be extremely different than far-field (FF) ground motion records and demonstrate unusual spectral shape, as well as large amplitude and different energy content (Veismoradi and Darvishan, 2018). In near-fault (NF) zones, due to the short distance between the rupturing fault and building site, high-frequency damping is minimal, and thus their records include high-frequency contents (Stewart et al., 2002). However, the most prominent characteristics of the near-fault earthquake could be devoted to the predominant velocity pulse (also known as pulse-like ground motions (PL)), being able to emerge from either the effect of forward directivity or fling step (Veismoradi and Darvishan, 2018). Forward-directivity appears when the surface rupture extends toward the site, while the fling step is due to permanent ground displacement caused by tectonic deformation (Kalkan and Kunnath, 2006). Further observations revealed that the major response of structures owing to a near-fault earthquake with effects of fling-step (permanent displacement at the strikeparallel direction of a strike-slip fault) was achieved at the first mode and wavelike vibrations with no fling-effect cause major response of structure was achieved at the structures' higher modes (Kalkan \& Kunnath, 2006). Under near-fault earthquakes with pulse velocities greater than 0.70s, (Gerami and Abdollahzadeh, 2013) studied steel moment-resisting frames and revealed that forward-directivity effects raised the local and global demands around 1.1-2.6 and 1.2-3.5 times, respectively (Gerami and Abdollahzadeh, 2013). Eskandari et al. (2017) compared the seismic performance of reinforced concrete steel braced frames against far-field and near-fault seismic records and witnessed more result dispersions of NF records for the intermediate and high-rise frames. Besides, Mashayekhi et al. (2019) illustrated that structures' inter-story drift angle under near-fault earthquakes with the effect of forward-directivity was greater than far-fault earthquakes for approximately $30-50 \%$ of structure height in upper stories.

On the other hand, valuable research has been recently done on the optimization and improvement of steel structure design relationships using an Adaptive Neuro-Fuzzy Inference System. Artificial neural networks (ANNs) and adaptive neuro-fuzzy inference system (ANFIS) methods are developed and employed to detect damage, applying dynamic parameters of Hakim and Abdul Razak (2013), in a steel girder bridge model. Basarir et al. (2019) studied different modelling methods, including adaptive neuro-fuzzy inference system (ANFIS) and multiple regression, to predict the final pure bending of concrete-filled steel tubes (CFTs). They revealed that the ANFIS model is able to predict the final pure bending of CFT with high accuracy (Basarir et al., 2019).

This article proposes an intelligence model for predicting the roof ductility of the EBFs. This model is presented on the basis of geometrical characteristics of EBFs and achieved according to the parametric investigation, such as various nonlinear time history analyses of 162 EBFs with 4 performance levels under 20 near-fault ground motions. The considered geometrical characteristics include the number of stories, the stiffness of the columns, the brace slenderness, and the ratio of the link beam length to the total length of the beam. For this purpose, it is necessary to prepare a large database of studies of a considerable number of frames with an eccentrically braced frame system using nonlinear dynamic analysis. Therefore, a total of 12960 nonlinear analyses were 
performed based on a platform of Incremental Dynamic Analysis (IDA) to create a database containing a wide range of relevant data. Then, an Adaptive Neuro-Fuzzy Inference System is employed to create an intelligent model for establishing the intelligence model. It may be supposed that the results of the suggested patterns match the exact outcomes of nonlinear time history analyses. The main emphasis is on introducing the potential of the proposed relationships to fit them into the framework of design methods based on the elastic analysis.

The results are principally applied to structures under far-field earthquakes, although many studies have been performed to propose more applicative $R-\mu$ relationships. Results are unavailable concerning the $R-\mu$ relationships for structures exposed to severe NF-PL ground motions. Generally, the structural responses because of NF-PL are coupled with FF-induced ones, making it complex to create rational responses. Another highlight of this paper is the introduction of an intelligence model to estimate the required coefficients. To achieve this goal, an Adaptive NeuroFuzzy Inference System has been utilized.

\section{Adaptive Neuro-Fuzzy Inference System}

The need to solve the complex, nonlinear, and variable problems grows with time. Conventional mathematical models perform linear and constant analysis effectively. Although techniques that work on a particular model are capable of analysing complex nonlinear and time-varying problems, they also face some limitations. Combining these with other issues like decision making has inspired the development of intelligent techniques, including fuzzy logic, genetic algorithms, neural networks, and expert systems. Intelligent systems mainly employ a combination of these techniques to solve very complex problems. Although fuzzy logic and artificial neural networks both have been very successful in solving time-varying nonlinear problems, each has its own limitations, reduces their use in solving many of these problems (Straccia, 2013).

Determining the exact number of rules and functions of membership in fuzzy logic is extremely difficult and time-consuming for complex problems. Optimizing fuzzy solutions is also much more time-consuming and difficult. Understanding the nature of the neural networks and how they learn about the relationship between inputs and outputs is very complicated (Nikravesh, 2007). Neural network technology can be applied to learn system behaviour based on input and output data ( Straccia, 2013). This knowledge may be applied to create fuzzy rules and membership functions, thus reducing development time. Fuzzy neural systems can create fuzzy rules and membership functions of complex systems that fuzzy logic technology alone has problems with. The use of nonheuristic algorithms in fuzzy neural systems increases the accuracy, performance, and reliability of these systems and generally reduces costs. The ability to optimize the fuzzy neural system is one of their key capabilities. Membership rules and functions of a fuzzy neural system can be optimized by applying neural network algorithms. These systems can use fuzzy rules to estimate the neural network weights.

Neural-Fuzzy Systems was introduced first by Jang (1993). A fuzzy inference system can be created if there is knowledge based on linguistic-fuzzy rules. To create a fuzzy inference system (FIS), it is necessary to specify fuzzy sets and operators; in order to construct a neural network, the structure and learning algorithm must be specified. Research shows that each of these methods has its drawbacks. It is, therefore, natural that to enhance the level of these methods, they must be combined. What the FIS cannot do, is to learn; thus, the ability of learning is vital from the FIS point of view. Artificial neural network learning algorithms determine FIS parameters in the structure of a fuzzy-neural system. In a fuzzy-neural system, data-based structures participate as 
International Journal of Mathematical, Engineering and Management Sciences

Vol. 5, No. 6, 1516-1537, 2020

https://doi.org/10.33889/IJMEMS.2020.5.6.112

input data. A prevalent manner to use a learning algorithm in FIS is to present the FIS system in a structure such as neural networks (Jang, 1993). ANFIS uses a Sugeno-type fuzzy system in the five-layer network (the input layer not counted by Jang), as demonstrated in Figure 1 for two inputs $x$ and $y$ and one output $z$.

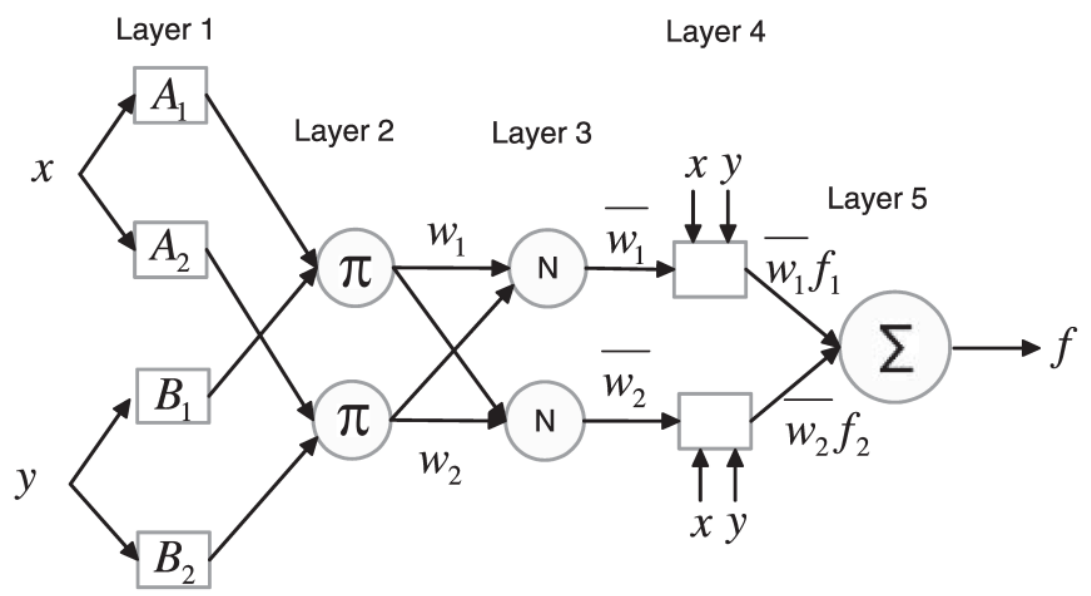

Figure 1. ANFIS architecture for two input data, $x$ and $y$ (Jang, 1993)

In the first layer, also called the fuzzy layer, the membership degree of each linguistic variable is calculated. For instance, if there are only two membership functions for each of the inputs $x$ and $y$, the output of this layer will be as Equations (1) and (2):

$O_{i}^{1}=\mu_{A i}(x), \quad i=1,2, \ldots, n$

$O_{i}^{1}=\mu_{B i}(y), \quad i=1,2, \ldots, n$

where $x$ and $y$ are the input to node $i$, and $A_{i}$ and $B_{i}$ are the linguistic labels (such as "small" or "large") related to this node function. Put it differently, $O_{i}^{1}$ denotes the membership function of $A_{i}$ and $B_{i}$; it indicates the extent to which $x$ satisfies the quantifier $A_{i}$ and $B_{i}$.

In the second layer, part (and) of the (If-Then) fuzzy system rules is considered as a product. Fuzzy (If-Then) rules are determined as Equation (3) in ANFIS.

IF $x$ is $A_{i}$ and $y$ is $B_{i}$

THEN $f_{i}=p_{i} x+q_{i} y+r_{i}$

$i=1,2, \ldots, n$

where $n$ is the number of rules and parameters that are specified during the training phase. The output of this layer is obtained by Equation (4). 
International Journal of Mathematical, Engineering and Management Sciences

Vol. 5, No. 6, 1516-1537, 2020

https://doi.org/10.33889/IJMEMS.2020.5.6.112

$w_{i}=\mu_{A i}(x) \times \mu_{B i}(x), \quad i=1,2, \ldots, n$

In the third layer, called the normalized layer, the weights calculated in the previous layer are normalized by Equation (5).

$\bar{w}_{i}=\frac{w_{i}}{\sum_{i=1}^{n} w_{i}}, \quad i=1,2, \ldots, n$

The fourth layer is the de-fuzzy layer. In this layer, each node affects the estimation of the system output by multiplying its normalized weight in the $f_{i}$ as illustrated in Equation (6).

$O_{i}^{4}=\bar{w}_{i} f_{i}=\bar{w}_{i}\left(p_{i} x+q_{i} y+r_{i}\right), \quad i=1,2, \ldots, n$

where $\overline{w_{i}}$ denotes layer 3 output, and $p_{i}, q_{i}, r_{i}$ indicates the parameter set. In this layer, parameters are referred to as consequent adjustable parameters.

Finally, in the fifth layer, all the signals proposed to the layer are assembled based on Equation (7) and considered as the system's output manager.

$O_{i}^{5}=$ Overal output $=\sum_{i=1}^{n} \bar{w}_{i} f_{i}, \quad i=1,2, \ldots, n$

\section{Creating the Databank}

\subsection{Design and Analysis of Non-Linear Models}

This study is based on 2-D regular frames with a constant height of 3 meters and 5 meters' bays. The columns are pinned connected to the base, and capable of conveying the moment forces along with their height. The beams are also pinned linked to the columns. Dead and live uniform loads

on beams are 2500 and $1000 \mathrm{~kg} / \mathrm{m}$, respectively. Furthermore, the yield stress of steels is considered $2400 \mathrm{~kg} / \mathrm{cm}^{2}$. The number of stories, $n_{s}$, is considered to be $3,6,9,12,15$, and 20 . The characteristic configuration of 2-D frames is illustrated in Figure 2. The basic period of the frames is calculated by using the relation $\mathrm{T}=0.08 \mathrm{H}^{0.75}$ and considering $\mathrm{H}$ as the total height of the frames (No, 2005). Link beams have been categorized into short, intermediate, and long length, similar to the ones specified in earlier studies (Rossi and Lombardo, 2007; Bosco and Rossi, 2009; Kuşyılmaz and Topkaya, 2013). The link behaviour is controlled by shear for values less than $1.6 M \mathrm{p} / \mathrm{Vp}$ (where $M \mathrm{p}$ and $V \mathrm{p}$ represent the plastic moments and the plastic shear strengths, respectively), while it is controlled by flexure for values greater than $2.6 \mathrm{Mp} / \mathrm{Vp}$. A combination of shear and flexural yielding occurs for link lengths between $1.6 \mathrm{Mp} / \mathrm{Vp}$ and $2.6 \mathrm{Mp} / \mathrm{Vp}$, (AISC, 2010). Hence, models have been developed for these triple link beam length ratios $(\xi=\mathrm{e} / \mathrm{L}), 0.2,0.35$, and 0.50 .

Moreover, each model has been expanded with brace slenderness, $\lambda$, in triple level. The slenderness of braces is obtained using Equation (8) (Karavasilis et al., 2007). 
$\lambda=\frac{l}{\pi \cdot r} \sqrt{\frac{F_{y}}{E}}$

where $l$ represents the length of the braces, $r$ denotes the gyration radius of the bracing section, $F_{y}$ represents the applied yielding stress of the steel, and $E$ denotes Young's modulus of materials.

The effect of the columns' stiffness is given by a coefficient, $\alpha$, as calculated by Equation (9) (Karavasilis et al., 2007).

$\alpha=\frac{n_{c} \cdot I_{c} \cdot L_{d}}{n_{d} \cdot A_{d} \cdot h^{3} \cdot \cos ^{2} \theta}$

where $n_{c}$ and $n_{d}$ indicate the number of columns and braces in a story, respectively. $I_{c}$ represents the second moment of inertia of the columns, $h$ denotes the floor height, and $\theta$ indicates the angle between the brace and the beam.

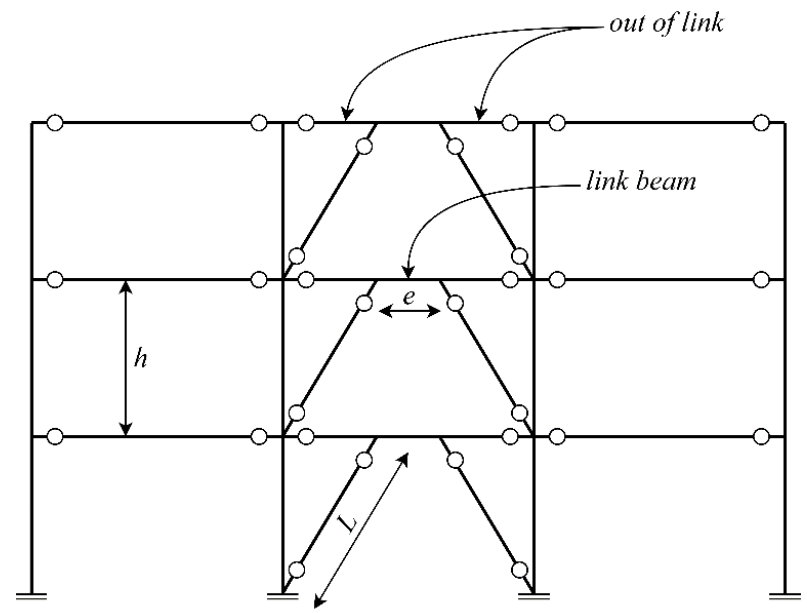

Figure 2. Typical configuration of EBFs

Diagonal braces, columns, and beam segments in link outside are modelled to stay basically elastic on the basis of capacity design concepts (Özhendekci and Özhendekci, 2008; Kuşyllmaz and Topkaya, 2015). Such members need, therefore, have sufficient strength to resist forces relative to the link expected strength, such as strain hardening (Fakhraddini et al., 2019). The braces are developed in order to have adequate resistance because of seismic loading equal to forces created by adjusted link shear strength. The beam design outside the link is like the brace. The columns are adapted for resisting the forces made by the adjusted shear strength of all links above the column level.

The EBFs have been designed using LRFD method, under AISC 360-10 (AISC, 2010) using ETABS (2016) software (Habibullah, 2016). Accordingly, a database family of models is produced at $6\left(n_{s}\right) * 3(\alpha) * 3(\lambda) * 3(\xi)=162$ members. In the following, all EBFs have extended with 4 various rotation angles of link beams values, accordance with the 4 performance levels. The first 
performance level is related to forming the first plastic hinge in the link beam, and the rest of the performance levels taken from ASCE41-13 (Pekelnicky et al., 2012) corresponded to the angle of rotation of the link beam. Using Equation $\Delta_{\mathrm{i}}=\gamma_{\mathrm{i}} \mathrm{eh} / \mathrm{L}$, for the quadruple performance levels extracted from ASCE41-13 (Pekelnicky et al., 2012) for the different link beam lengths, the maximum displacement is related to the link beam rotation. $\Delta_{i}, \gamma_{i}, e, h$, and $L$ are displacement, link beam rotation, link beam length, story height, and brace length, respectively. Moreover, extended EBFs are analysed under 20 pulse-like near-fault earthquakes. For the nonlinear time history analyses, OpenSEES (McKenna, 2011) software has been used.

The link beam inelastic response, in EBFs, has been modelled using the method suggested by Bosco et al. (2015). The flexural bending and shear force effect is simulated by the model on the link beams' inelastic behaviour with short, intermediate, as well as long length. The link model consists of five elements joined in series, as illustrated in Figure 3. The middle element (EL0) has the same length and moment of link inertia, allowing its flexural elastic response to be reflected. In this simulation, two zero-length elements (EL1 and EL2) exist. The elastic and inelastic shear response of half a link is taken into account by EL1, while the inelastic flexural response of the ending part of the link is taken into account by EL2. Independent relative vertical displacements and relative rotations are allowed in the nodes EL1 and EL2, respectively (Bosco et al., 2015). With the help of elastic elements, beams, columns, braces, and beam segments outside the links are modelled to remain elastic basically. In the analyses, the Rayleigh damping is regarded. In order that the frame first to third modes are defined by an equivalent viscous damping factor of 0.05 , stiffness and mass coefficients are determined.

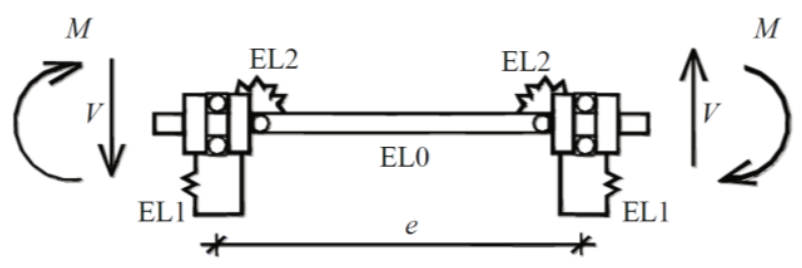

Figure 3. Modeling of the link (Bosco et al., 2015)

\subsection{Near-Fault Records}

Near-fault earthquakes are selected based on the classification presented in Baker's study (Baker, 2007). The features of the chosen earthquakes are presented in Table 1. As a result, the final database will be $162 * 4 * 20=12960$.

In order to produce the expected database, 12960-time history analyses are performed based on an IDA analysis platform using OpenSEES (McKenna, 2011) software. In this regard, each accelerometer is repeatedly affected by multiplying the accelerometer in a Scale-Factor $(S F)$ coefficient. Corresponded to the performance levels, the maximum inter-story drift of the frame is compared to the target values of ASCE41-13 (Pekelnicky et al., 2012) in each iteration. The repeat operation continues until the expected values are reached and then stops (Tzimas et al., 2017). The appropriate coefficient for different performance levels is calculated using the Bayesian method. This process is performed for a specific performance level based on the flowchart shown in Figure 4 for a single earthquake (Tzimas et al., 2017). 
International Journal of Mathematical, Engineering and Management Sciences

Vol. 5, No. 6, 1516-1537, 2020

https://doi.org/10.33889/IJMEMS.2020.5.6.112

Table 1. Characteristics of near-fault earthquakes applied in the study

\begin{tabular}{|c|l|c|l|c|c|c|}
\hline Record No. & \multicolumn{1}{|c|}{ Earthquake Name } & Year & \multicolumn{1}{|c|}{ Station Name } & PGA $^{\mathbf{a}}(\mathbf{g})$ & $\mathbf{M w}^{\mathbf{b}}$ & $\mathbf{R}^{\mathbf{c}}(\mathbf{k m})$ \\
\hline 1 & Imperial Valley-06 & 1979 & EC County Center FF & 0.179721 & 6.53 & 7.31 \\
\hline 2 & Imperial Valley-06 & 1979 & El Centro Array \#7 & 0.462394 & 6.53 & 0.56 \\
\hline 3 & Imperial Valley-06 & 1979 & El Centro Array \#8 & 0.467966 & 6.53 & 3.86 \\
\hline 4 & Imperial Valley-06 & 1979 & El Centro Differential Array & 0.417229 & 6.53 & 5.09 \\
\hline 5 & Morgan Hill & 1984 & Coyote Lake Dam (SW Abut) & 0.813971 & 6.19 & 0.53 \\
\hline 6 & Loma Prieta & 1989 & LGPC & 0.943935 & 6.93 & 3.88 \\
\hline 7 & Landers & 1992 & Lucerne & 0.704174 & 7.28 & 2.19 \\
\hline 8 & Landers & 1992 & Yermo Fire Station & 0.235782 & 7.28 & 23.62 \\
\hline 9 & Northridge-01 & 1994 & Jensen Filter Plant & 0.517814 & 6.69 & 5.43 \\
\hline 10 & Northridge-01 & 1994 & Newhall - Fire Sta & 0.723597 & 6.69 & 5.92 \\
\hline 11 & Northridge-01 & 1994 & Rinaldi Receiving Sta & 0.869806 & 6.69 & 6.50 \\
\hline 12 & Northridge-01 & 1994 & Sylmar - Converter Sta & 0.594294 & 6.69 & 5.35 \\
\hline 13 & Northridge-01 & 1994 & Sylmar - Converter Sta East & 0.828472 & 6.69 & 5.19 \\
\hline 14 & Northridge-01 & 1994 & Sylmar - Olive View Med FF & 0.732606 & 6.69 & 5.30 \\
\hline 15 & Kobe, Japan & 1995 & KJMA & 0.854262 & 6.90 & 0.96 \\
\hline 16 & Kobe, Japan & 1995 & Takarazuka & 0.645232 & 6.90 & 0.27 \\
\hline 17 & Kocaeli, Turkey & 1999 & Gebze & 0.241333 & 7.51 & 10.92 \\
\hline 18 & Chi-Chi, Taiwan & 1999 & TCU049 & 0.286217 & 7.62 & 3.78 \\
\hline 19 & Chi-Chi, Taiwan & 1999 & TCU053 & 0.224488 & 7.62 & 5.97 \\
\hline 20 & Chi-Chi, Taiwan & 1999 & TCU068 & 0.564477 & 7.62 & 0.32 \\
\hline
\end{tabular}

Peak Ground Acceleration, ${ }^{\mathrm{b}}$ Moment Magnitude, ${ }^{\mathrm{c}}$ Closest distance from the recording site to the ruptured area

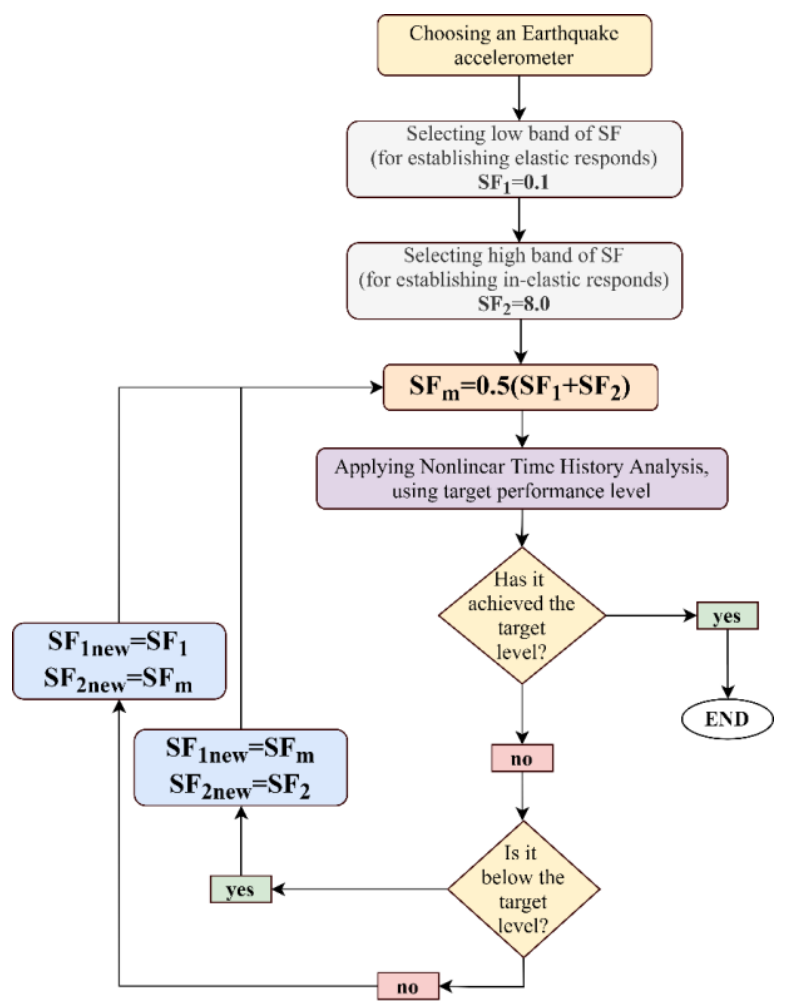

Figure 4. Flowchart of the change in scale factor 
International Journal of Mathematical, Engineering and Management Sciences

Vol. 5, No. 6, 1516-1537, 2020

https://doi.org/10.33889/IJMEMS.2020.5.6.112

Researchers have been criticized for scaling, especially when they are above 10 or even 12 (De et al., 2009; Hancock, 2006), cause that the results within the range of normal earthquakes have led to the elimination of some of the data that claims higher than 12 from the databank. This screening eventually results in the use of a 9026 net databank from 12960 data. For each data, the maximum roof displacement, $u_{r \max }$, and inter-story drift, $I D R_{\max }$, are calculated.

\subsection{Verification}

Modelling validation is one of the most important and fundamental steps in any study. This is especially important for analytical studies that require a large database. It is clear that if modelling assumptions have errors, the results applied in empirical extensions will also be inaccurate. Therefore, for validation, a 6-story structural model has been developed from the study of (Fakhraddini et al., 2019). The frame is schematically similar to that shown in Figure 2 Also, 144 and 360in show the uniform story height and bay length, respectively. Considering L, as the length of the beam, three different values, 0.1, 0.3, and 0.5, have been taken as $a$ to create three different link beam values. These link beam lengths have been categorized into short, intermediate, and long lengths, similar to ones shown in earlier studies (Bosco and Rossi, 2009; Kuşy1lmaz and Topkaya, 2013; Rossi and Lombardo, 2007). The link behaviour is controlled by shear for values less than $1.6 M_{\mathrm{p}} / V_{\mathrm{p}}$ (where $M_{\mathrm{p}}$ and $V_{\mathrm{p}}$ represent the plastic moments and the plastic shear strengths, respectively), while it is controlled by flexure for values greater than $2.6 M_{\mathrm{p}} / V_{\mathrm{p}}$. A combination of shear and flexural yielding occurs for link lengths between $1.6 M_{p} / V_{p}$ and $2.6 M_{p} / V_{p}$ (Committee, 2010). All frames include three bays with simple beam-to-column connections. All beams' uniform dead and live loads are 0.12 and $0.06 \mathrm{kips} / \mathrm{in}$, respectively; all frames' seismic floor masses are regarded as 206 kips. A steel grade of A992 with a yield strength of $50 \mathrm{ksi}$ is applied in designing all structural members. The final section sizes of frames are summarized in Table 2. The EBFs provided in Table 2 are analysed in order to define their response to the 15 seismic excitations. The sections mentioned in the Table 2 are $\mathrm{W}$-type for beams and columns. For this purpose, typically the expression $3(381414)+3(14 \times 30)$ means that for the three lower and upper floors, sections $\mathrm{W} 14 \times 38$ and W14 $\times 30$ have been used, respectively. HSS sections have also been used for all braces. For the nonlinear time history analyses, OpenSEES software is used. The link beam inelastic response is modelled using the method suggested by (Bosco et al., 2015). For every ground motion, the scale factor $(S F)$ of the ground motion, related to Life Safe (LS) performance level, is defined via incremental dynamic analysis (IDA) on the basis of acceptance criteria of ASCE 41-13 (Pekelnicky et al., 2012). As a final point, the median peak floor displacements are recorded vs the responses from the OpenSEES shown in Figure 5 In this study, the comparison of the diagrams presented attests to the adequate accuracy of the modelling phase.

Table 2. Section sizes of the 6St-EBFs in Fakhroddini et al. (Fakhraddini et al., 2019)

\begin{tabular}{|c|c|c|c|c|c|}
\hline $\begin{array}{c}\text { Link length } \\
\boldsymbol{a}=\boldsymbol{e} / \boldsymbol{L}\end{array}$ & Side columns & Middle columns & Link beam* & Gravity beams $^{*}$ & Brace $^{* *}$ \\
\hline 0.1 & $\begin{array}{c}3(14 \times 38)+ \\
3(14 \times 38)\end{array}$ & $\begin{array}{c}3(14 \times 311)+ \\
3(14 \times 132)\end{array}$ & $2(14 \times 53)+3(14 \times 48)$ & $14 \times 109$ & $5(6 \times 1 / 2)+6 \times 1 / 4$ \\
\hline 0.3 & $\begin{array}{c}3(14 \times 38)+ \\
3(14 \times 30)\end{array}$ & $\begin{array}{c}3(14 \times 311) \\
+3(14 \times 132)\end{array}$ & $4(14 \times 68)+2(14 \times 48)$ & $14 \times 109$ & $3(6 \times 1 / 2)+3(6 \times 1 / 4)$ \\
\hline 0.5 & $\begin{array}{c}3(14 \times 38)+ \\
3(14 \times 30)\end{array}$ & $\begin{array}{c}3(14 \times 426)+ \\
3(14 \times 176)\end{array}$ & $2(14 \times 132)+4(14 \times 68)$ & $14 \times 109$ & $4(6 \times 1 / 2)+2(6 \times 1 / 4)$ \\
\hline
\end{tabular}

${ }^{*}$ These sections are W-type. ${ }^{* *}$ These sections are HSS-type. 


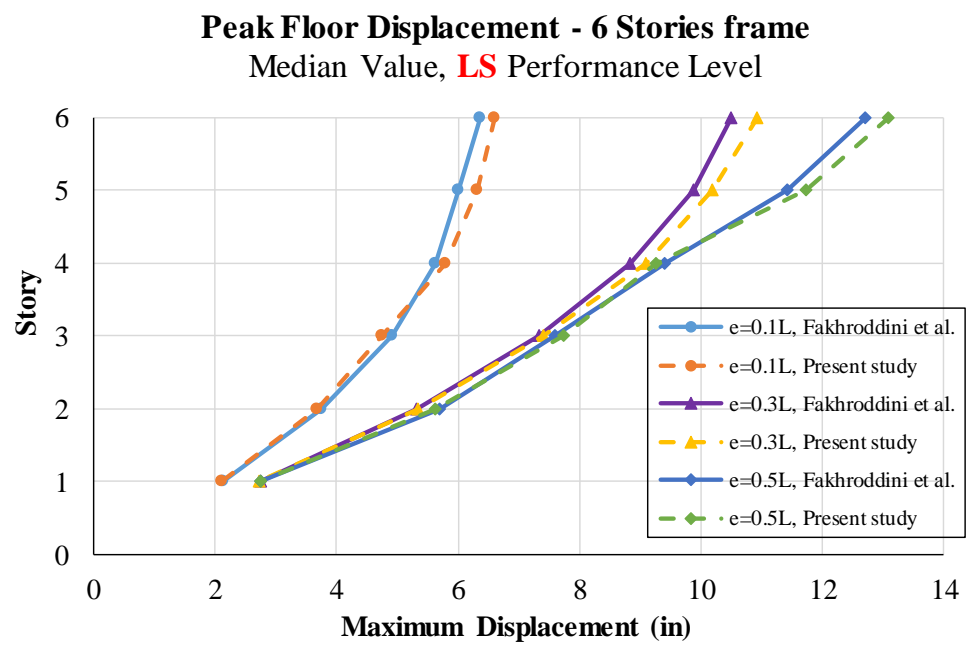

Figure 5. Model validation in comparison with the result of Fakhroddini et al. (Fakhraddini et al., 2019)

\section{Using ANFIS to Develop the Intelligent Model}

Different parameters are selected for this study. Considering the procedure explained in the previous section, 12960 data are calculated and applied. The selected data are divided into two groups: one group, including 6769 data sets, is applied as training data to develop the model, and the other group, including 2257 data sets, is applied as testing data to verify the model validation. The training and testing data are selected randomly. Proper selection of input and output data can be the first and foremost step in designing intelligent and predicting systems. The input data consists of the number of stories, beam link length to the beam length ratio, braces slenderness, stiffness of columns, fundamental period of the structure, roof ductility, and behaviour factor within the ranges, as presented in Table 3. Figure 6 illustrates the schematic of the input and output parameters applied in ANFIS.

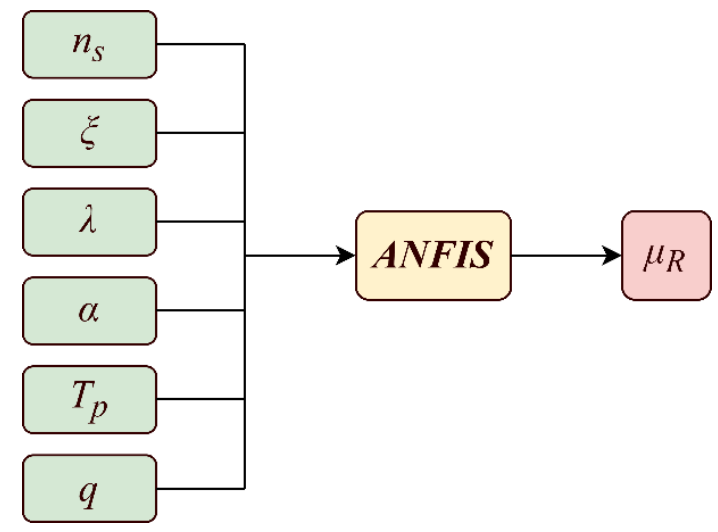

Figure 6. Schematic of the input and output parameters of the ANFIS 
International Journal of Mathematical, Engineering and Management Sciences

Vol. 5, No. 6, 1516-1537, 2020

https://doi.org/10.33889/IJMEMS.2020.5.6.112

Table 3. Range of the data applied

\begin{tabular}{|c|c|c|c|c|c|c|}
\hline \multirow{2}{*}{ Parameter } & \multicolumn{2}{|c|}{ Number of the data } & \multicolumn{2}{c|}{ Range of data } & \multicolumn{2}{c|}{ Mean data } \\
\cline { 2 - 7 } & Training data & Testing data & Training data & Testing data & Training data & Testing data \\
\hline$n_{s}$ & 6769 & 2257 & $3-20$ & $3-20$ & 11.7959 & 11.7939 \\
\hline$\xi$ & 6769 & 2257 & $0.2-0.5$ & $0.2-0.5$ & 0.34386 & 0.34381 \\
\hline$\lambda$ & 6769 & 2257 & $0.22135-0.82729$ & $0.22135-0.82729$ & 0.39832 & 0.39835 \\
\hline$\alpha$ & 6769 & 2257 & $0.00362-0.06122$ & $0.00362-0.06122$ & 0.01540 & 0.01540 \\
\hline$T_{p}$ & 6769 & 2257 & $0.952-12.845$ & $0.952-12.845$ & 5.06167 & 5.0688 \\
\hline$\mu_{R}$ & 6769 & 2257 & $0.35908-11.9994$ & $0.46211-11.9818$ & 3.81001 & 3.76826 \\
\hline$q$ & 6769 & 2257 & $1-11.956$ & $1-11.979$ & 2.52357 & 2.52901 \\
\hline
\end{tabular}

In order to find a proper association between these parameters for EDP prediction, several cases have been examined by previous researchers ( Karavasilis et al., 2007; Karavasilis et al., 2008). After several regressive examinations, they have established a powerful association between the independent parameters, a number of stories $\left(n_{s}\right)$, braces slenderness $(\lambda)$, stiffness of columns $(\alpha)$, a basic period of structure $\left(T_{p}\right)$, as well as roof ductility $\left(\mu_{R}\right)$ and $(q)$ for $\mathrm{CBF}^{1}$ steel frames under regular earthquakes as presented in Equations (10) and (11).

$q=1+p_{1} \cdot\left(\mu_{R}-1\right)^{p_{2}} f\left(n_{s}, \lambda, \alpha, \frac{T}{T_{p}}\right)$

$\mu_{R}=1+p_{1} \cdot\left(\mu_{l}-1\right)^{p_{2}} f\left(n_{s}, \lambda, \frac{T}{T_{p}}\right)$

In order to account for the effect of link beam length, $\xi$ is considered as an extra parameter to the function. Moreover, owing to the properties of near-fault earthquakes, parameter $T / T_{p}$, change to $T_{p}$. Therefore, the basic platform of the equation will change to the Equations (12) and (13). In other words:

$q=1+p_{1} \cdot\left(\mu_{R}-1\right)^{p_{2}} \cdot f\left(n_{s}, \lambda, \alpha, T_{p}, \xi\right)$

$\mu_{R}=1+p_{1} \cdot\left(\mu_{l}-1\right)^{p_{2}} f\left(n_{s}, \lambda, T_{p}\right)$

To be more exact, Equations (12) and (13) could be rewritten as Equations (14) and (15), respectively. According to Equations (14) and (15), the model inputs are determined as Figure 6.

$$
\begin{aligned}
& q=1+p_{1} \cdot\left(\mu_{R}-1\right)^{p_{2}} \cdot n_{s}{ }^{p_{3}} \cdot \lambda^{p_{4}} \cdot \alpha^{p_{5}} T_{p}^{p_{6}} \cdot \xi^{p_{7}} \\
& \mu_{R}=1+p_{8} \cdot\left(\mu_{\text {link }}-1\right)^{p_{9}} \cdot n_{s}^{p_{10}} \cdot \lambda^{p_{11}} T_{p}^{p_{12}} \cdot \xi^{p_{13}}
\end{aligned}
$$

\footnotetext{
${ }^{1}$. Centrally braced frame
} 
The roof ductility, $\mu_{R}$, is achieved by dividing the inelastic roof displacement, $\Delta_{i}$, by the yielding displacement, $\Delta_{y}$, obtained by nonlinear time history and pushover analysis, respectively. Moreover, $\mu_{\text {link }}$, which indicates the ductility of link beams, is calculated by Equation (16).

$\mu_{\text {link }}=\frac{\theta_{\max }}{\theta_{y}}$

where $\theta_{\max }$ and $\theta_{y}$ are the maximum inelastic rotation and the yielding rotation of the link beam, respectively. On the other hand, in EBFs, $\theta_{\max }$ is linked to $I D R_{\max }$ using Equation (17). $\theta_{y}$ is also obtained from the acceptable limits of the ASCE41-13 code, depending on the dependent performance level.

$\theta_{\max }=\frac{I D R_{\max } \times L}{e \times h}$

In Equation (17), e is the length of the link beam, $L$ is the length of the brace, and $h$ is the height of the floor.

To generate the structure of the Fuzzy Inference System (FIS), two different methods, including "Subtractive clustering" and "Fuzzy C-Means clustering (FCM)," are evaluated for $\left(\mu_{R}\right)$ prediction. Properties and parameter values of the constructed model are listed in Table 4, separated by the FIS type.

Table 4. Properties and parameter values of the constructed model

\begin{tabular}{|l|c|}
\hline \multicolumn{1}{|c|}{ Properties } & Value/Type \\
\hline Subtractive clustering & 0.75 \\
\hline Cluster radius & gaussmf \\
\hline Input membership function type & Linear \\
\hline Output membership function type & 5 \\
\hline Fuzzy C-Means clustering (FCM) & gaussmf \\
\hline Cluster numbers & Linear \\
\hline Input membership function type & Sugeno \\
\hline Output membership function type & 2 \\
\hline FIS type & 1000 \\
\hline Partition matrix exponent & $10^{-5}$ \\
\hline Maximum number of iterations & \\
\hline Minimum improvement & \\
\hline
\end{tabular}

The structure of the FIS model depends on the type of producer function. Table 5 summarizes the properties of different FIS types. Figures 7 to 8 illustrate the structure of the interface model created based on the FIS function (Subtractive clustering/FCM). Besides, in Table 6, the fuzzy operators applied according to different methods of generating a FIS are listed. Figure 9 illustrates the membership functions of the various inputs associated with the models created. 
International Journal of Mathematical, Engineering and Management Sciences

Vol. 5, No. 6, 1516-1537, 2020

https://doi.org/10.33889/IJMEMS.2020.5.6.112

Table 5. Properties of different FIS types

\begin{tabular}{|l|c|c|}
\hline \multicolumn{1}{|c|}{ Property } & \multicolumn{2}{c|}{ FIS type } \\
\hline & Subtractive clustering & FCM \\
\hline Number of nodes & 149 & 79 \\
\hline Number of linear parameters & 70 & 35 \\
\hline Number of nonlinear parameters & 120 & 60 \\
\hline Total number of parameters & 190 & 95 \\
\hline Number of training data pairs & 6769 & 6769 \\
\hline Number of testing data pairs & 2257 & 2257 \\
\hline Number of fuzzy rules & 10 & 5 \\
\hline
\end{tabular}

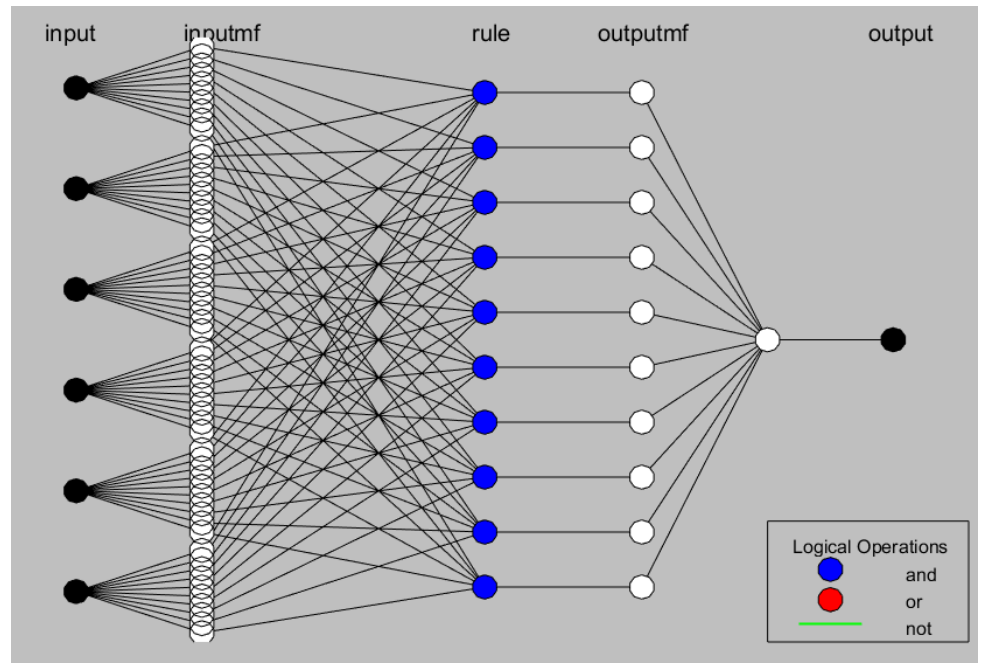

Figure 7. ANFIS structure for formulating input data using subtractive clustering method

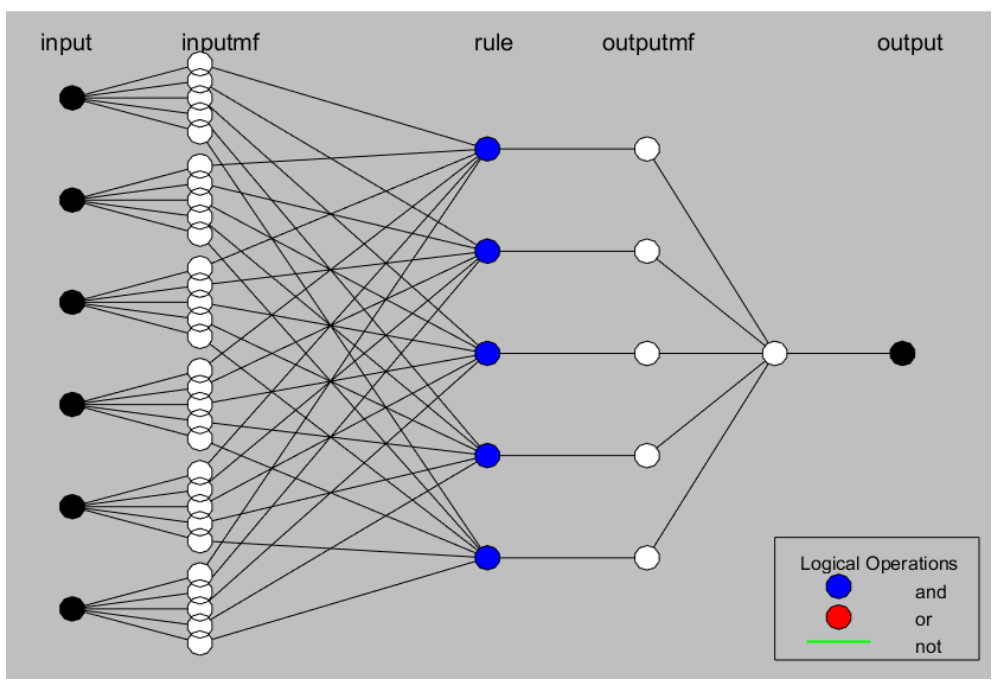

Figure 8. ANFIS structure for formulating input data using the FCM method 
International Journal of Mathematical, Engineering and Management Sciences

Vol. 5, No. 6, 1516-1537, 2020

https://doi.org/10.33889/IJMEMS.2020.5.6.112

Table 6. Parameters of the constructed model based on FIS

\begin{tabular}{|l|l|l|}
\hline \multicolumn{1}{|c|}{ Inference type } & \multicolumn{2}{c|}{ FIS type } \\
\hline & Subtractive clustering & FCM \\
\hline AND & Prod & Prod \\
\hline OR & Prober & Prober \\
\hline Implication & Prod & Prod \\
\hline Aggregation & Max & Max \\
\hline Defuzzification & Wtaver & Wtaver \\
\hline
\end{tabular}

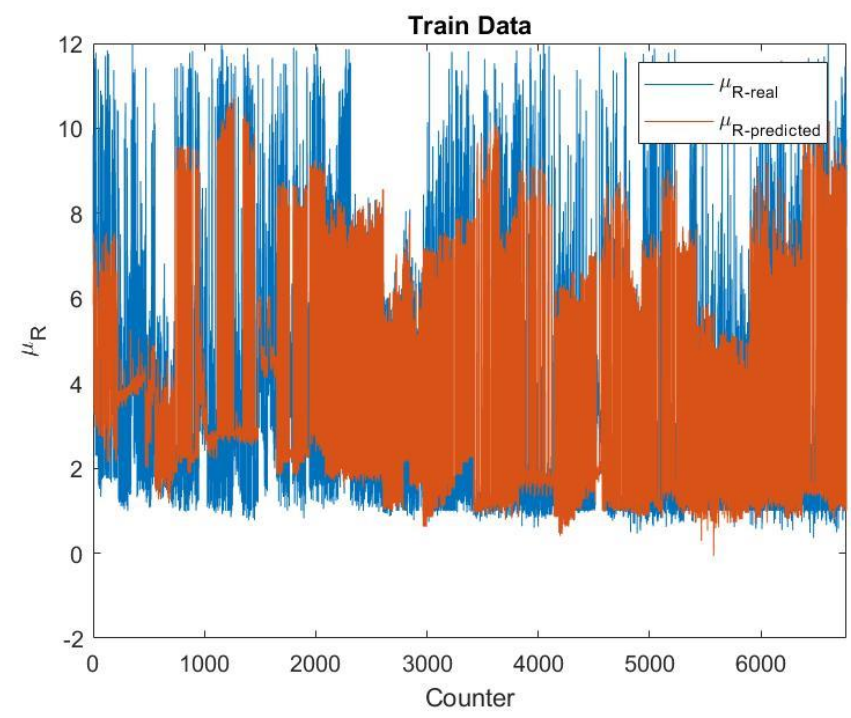

Figure 9. Comparison between the real and predicted value of $\left(\mu_{R}\right)$ in training data (Subtractive clustering method)

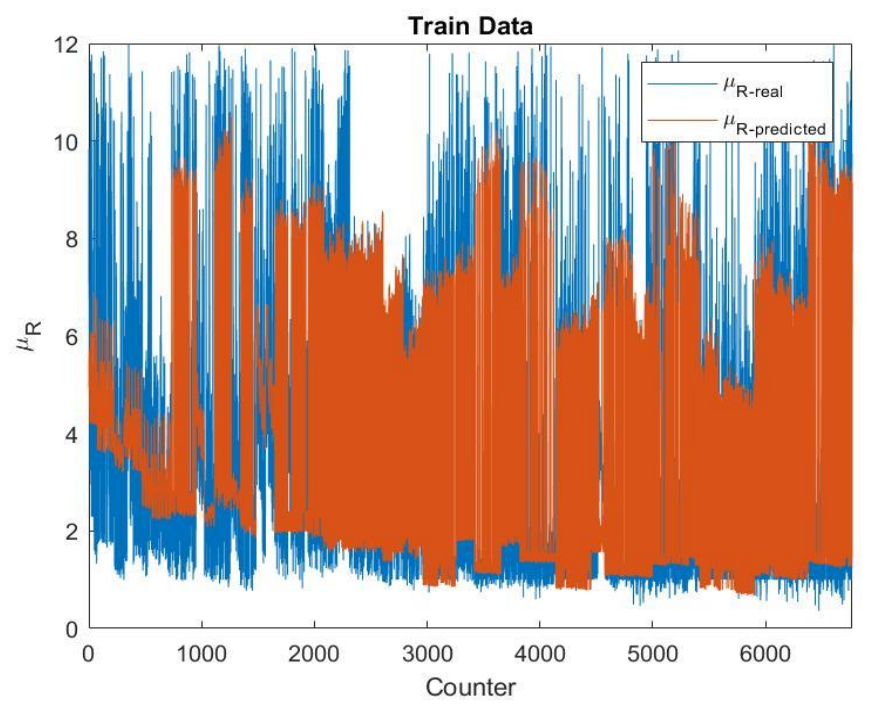

Figure 10. Comparison between the real and predicted value of $\left(\mu_{R}\right)$ in training data (FCM method) 
The comparisons between real and predicted values of $\left(\mu_{R}\right)$ are illustrated in Figures 9 and 10 for training data of Subtracting clustering and FCM methods. Based on the results, in both models, there is a good agreement between the model data and the real values in the training data. However, there is greater consistency in the model built on FCM. In these figures, the horizontal axis represents the number of data used and the vertical axis represents the values of each data.

In order to evaluate the model's efficiency and accuracy, various error criteria, including Error, Mean Error, Root Mean Square Error (RMSE), percentage of Mean Absolute Relative Error (MARE), and Correlation coefficient (R), are applied between model and real values. Equations (18) to (21) are applied to calculate each of the criteria, as mentioned earlier. The results of the calculation of these criteria are presented in Table 7 for the training data. The correlation comparison between real and predicted values are illustrated in Figures 11 and 12 for different types of FIS, considering the training data.

$$
\begin{aligned}
& \text { Error }=q_{\text {real }}-q_{\text {ANFIS results }} \\
& \text { Mean Error }=\frac{\text { Error }}{N} \\
& \text { RMSE }=\sqrt{\frac{\sum \text { Error }^{2}}{N}} \\
& \overline{\text { Error }}=\frac{\sum \text { Error }}{N}
\end{aligned}
$$

where $N$ is the number of datasets in the above relationships. As can be seen from Table 7. The model developed based on the Subtractive method provides more accurate results for predicting the behaviour factor in the range of training applied data.

Table 7. Results of evaluating different ANFIS models for training data

\begin{tabular}{|l|c|c|c|c|}
\hline FIS generation method & RMSE & Mean Error & Mean Absolute Relative Error & Correlation Coefficient(R) \\
\hline Subtractive method & 2.178 & $-6.28 \mathrm{E}-08$ & 0.3243 & 0.882 \\
\hline FCM & 2.282 & $-7.57 \mathrm{E}-09$ & 0.3255 & 0.876 \\
\hline
\end{tabular}


International Journal of Mathematical, Engineering and Management Sciences

Vol. 5, No. 6, 1516-1537, 2020

https://doi.org/10.33889/IJMEMS.2020.5.6.112

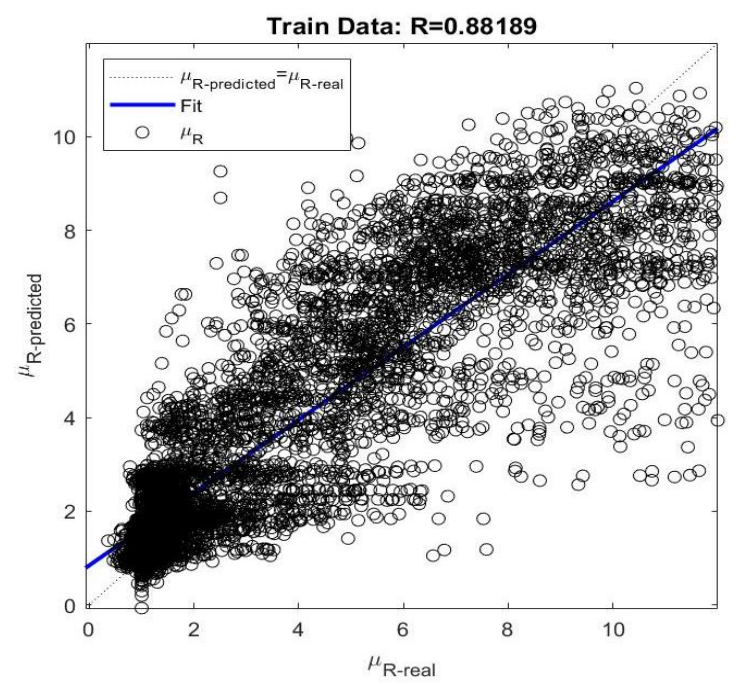

Figure 11. Correlation between the real and predicted values in training data (Subtractive clustering method)

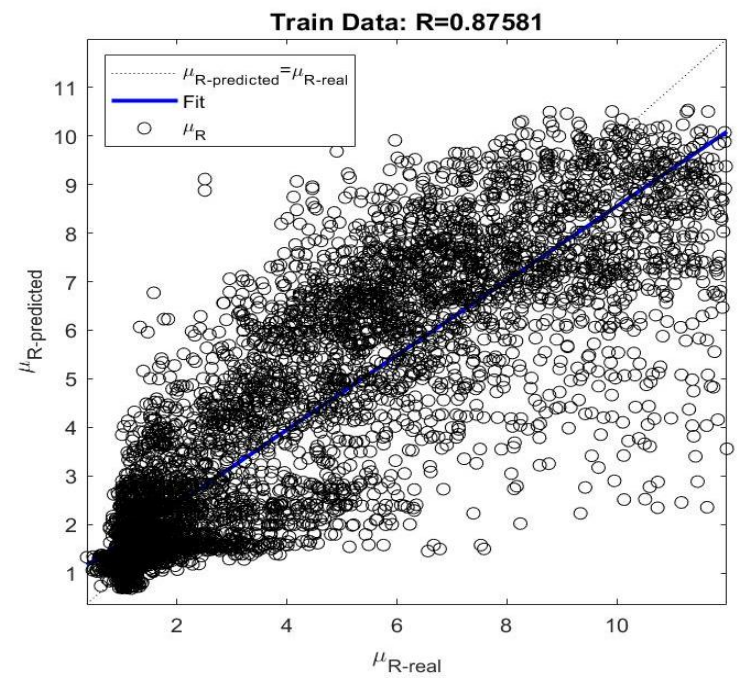

Figure 12. Correlation between the real and predicted values in training data (FCM method)

\section{Model Validation}

In order to validate and test the created models, test data consisting of 2257 categories, which make up about $25 \%$ of the total data, are applied. The results of the different models are illustrated in Figures 13 and 14 for the testing data. As can be observed, there is more agreement between the predicted data (model results), and the real values in the model developed based on the FCM method. 
International Journal of Mathematical, Engineering and Management Sciences

Vol. 5, No. 6, 1516-1537, 2020

https://doi.org/10.33889/IJMEMS.2020.5.6.112

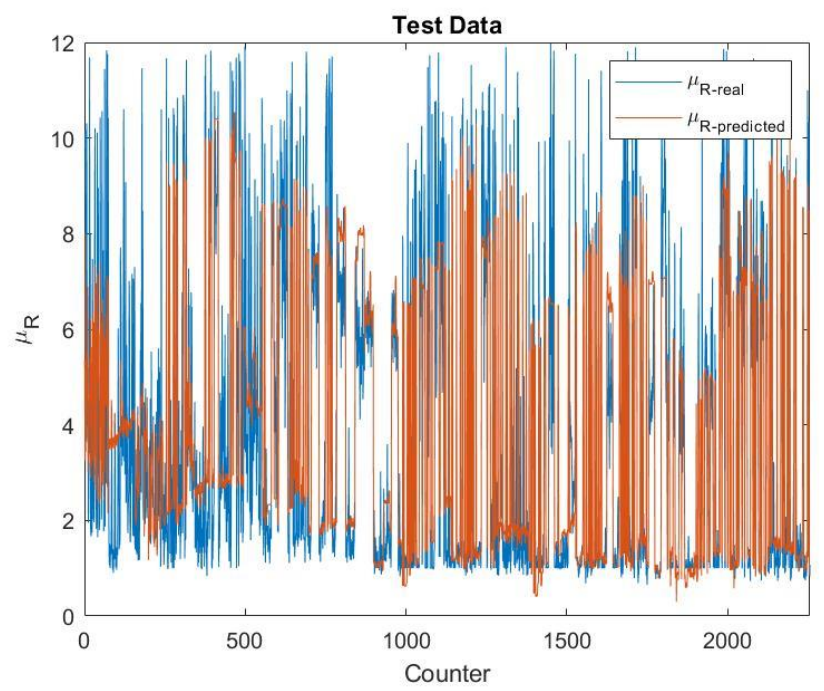

Figure 13. Comparison between the real and predicted value of $\left(\mu_{R}\right)$ in testing data (Subtractive clustering method)

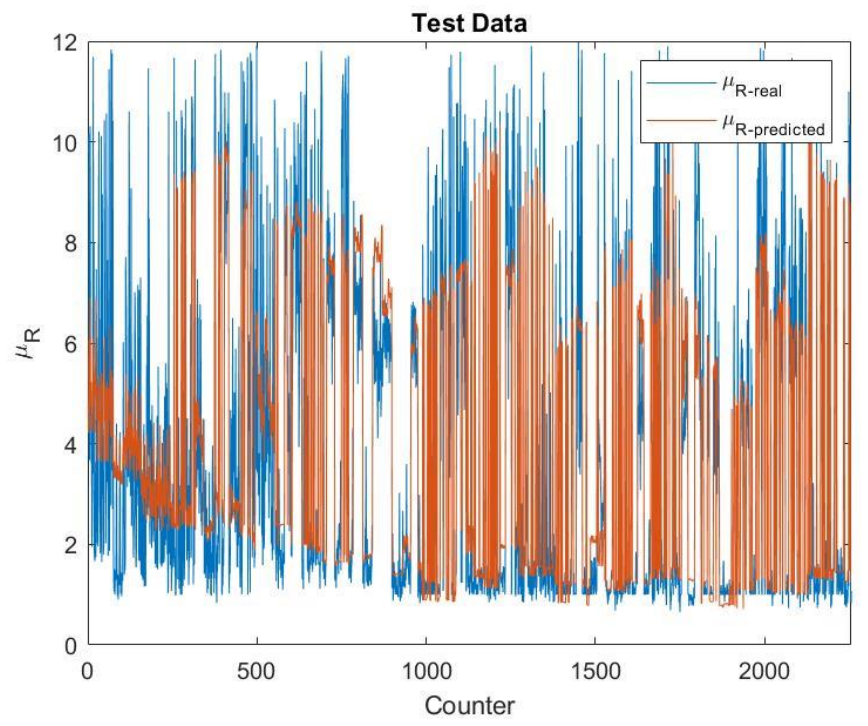

Figure 14. Comparison between the real and predicted value of $\left(\mu_{R}\right)$ in testing data (FCM method)

To evaluate the model's efficiency and accuracy, various error criteria, including Error, Mean Error, RMSE, MARE\%, and R, are applied between model and real values in the testing data. The results are presented in Table 8. It is again observed that the model created by FCM is more accurate than the model created based on Subtractive clustering. 
International Journal of Mathematical, Engineering and Management Sciences

Vol. 5, No. 6, 1516-1537, 2020

https://doi.org/10.33889/IJMEMS.2020.5.6.112

Table 8. Results of evaluating different ANFIS models for testing data

\begin{tabular}{|l|c|c|c|c|}
\hline FIS generation method & RMSE & Mean Error & Mean Absolute Relative Error & Correlation Coefficient $(\mathbf{R})$ \\
\hline Subtractive clustering & 2.145 & $-4.60 \mathrm{E}-02$ & 0.3289 & 0.888 \\
\hline FCM & 2.197 & $7.71 \mathrm{E}-03$ & 0.3215 & 0.885 \\
\hline
\end{tabular}

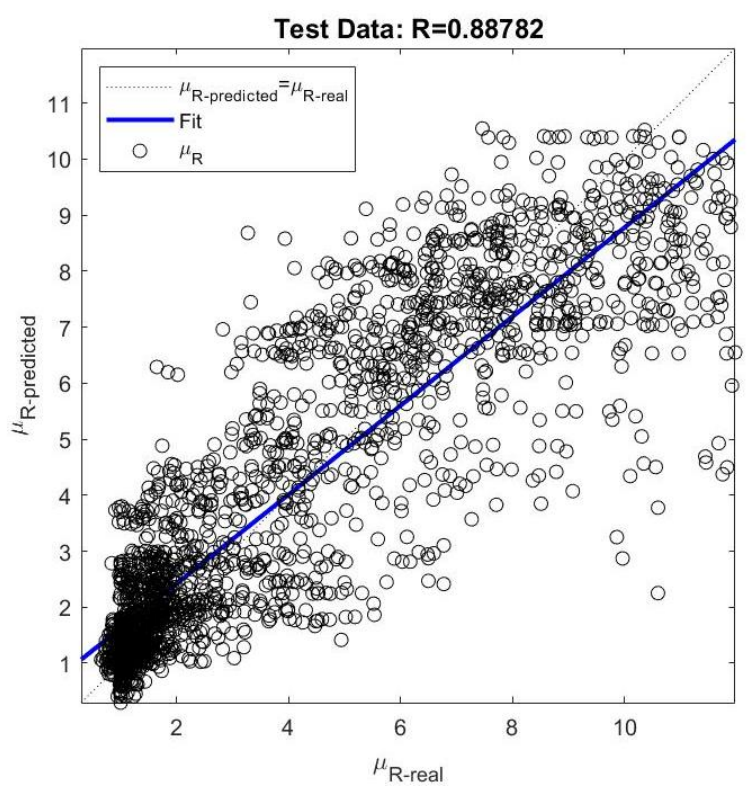

Figure 15. Correlation between the real and predicted values in training data (Subtractive clustering method)

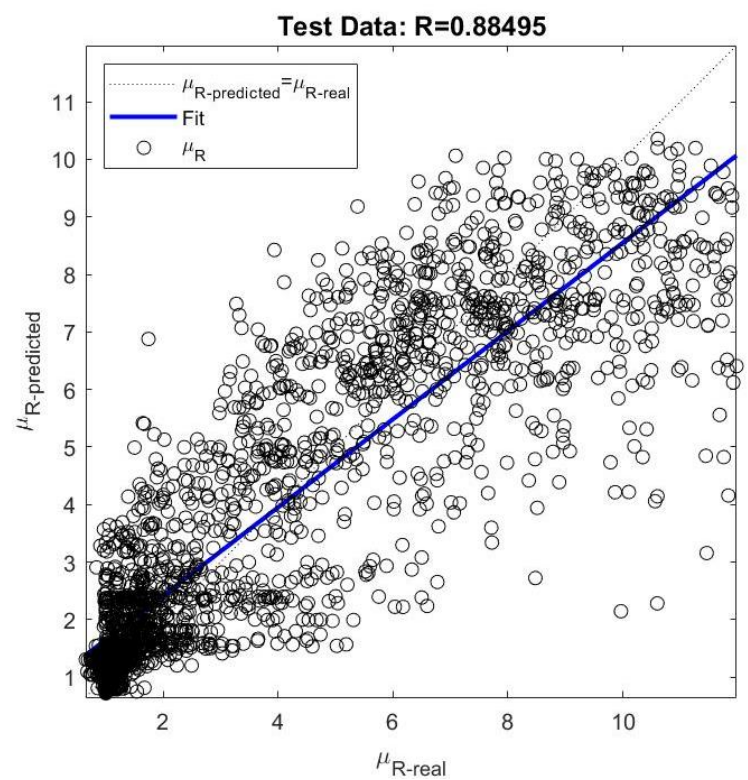

Figure 16. Correlation between the real and predicted values in training data (FCM method) 
The correlation between the results of different models and the real values are illustrated in Figures 15 and 16 for the testing data. Results show a higher correlation between the model results and the real values in the model created using the Subtractive method. Furthermore, the Error parameters in Table 8 show that the error generated by the model based on using the Subtractive method is less than the other models. Besides, the error range of the model mentioned above is lower than the others.

\section{Conclusion}

To sum, after studying a considerable number of EBF frames, nonlinear dynamic analysis of a large database was prepared. Out of 12960 data, 9027 data were applied to predict the neuro-fuzzy inference algorithm in the ANFIS system. Other data were eliminated based on factors, such as mathematical instabilities of nonlinear models, by performing a complex process. The main emphasis was on introducing the capability of the proposed model to fit into the framework of design methods based on a simple elastic analysis. An intelligent model was presented to estimate the global roof ductility $\left(\mu_{R}\right)$ for EBF steel frames under near-fault earthquakes. The produced intelligent model was a nonlinear function of the number of stories, brace slenderness, column stiffness, a basic period of the structure, link beam length to the total length of the beam ratio, design performance level, and behaviour factor of the structure. In order to create the best and most accurate model, Subtractive clustering and Fuzzy C-Mean clustering methods (FCM) were applied. Based on the results, the model developed by Subtractive clustering yielded more accurate outcomes than the models developed by the FCM method. The proposed model is an intelligent model in the range of data applied and can be applied to estimate the global roof ductility of EBFs. To evaluate the efficiency and performance of the model, both the correlation coefficient and common error calculation criteria, including RMSE and MARE, were applied. The correlation coefficient for the Subtractive clustering method was 0.888 based on the intelligent model in the testing data. On the other hand, the developed intelligent model can be applied as a precise alternative to predict $\left(\mu_{R}\right)$ for EBFs under near-earthquakes. From the results of this study, it can be pointed out that the developed intelligent model can be applied as an accurate substitute method to predict $\left(\mu_{R}\right)$ for EBF structures under near-fault earthquakes.

\section{Conflict of Interest}

The authors declare that they have no competing financial interests or personal relationships that have or could be perceived to have, influenced the work reported in this article.

\section{Acknowledgement}

The present study is a part of $\mathrm{PhD}$ dissertation of Seyed Abdonnabi Razavi, under the guidance of Dr. Navid Siahpolo and Dr. Mehdi Mahdavi Adeli in Islamic Azad University, Ahvaz branch.

\section{References}

AISC Committee (2010). Specification for structural steel buildings (ANSI/AISC 360-10). American Institute of Steel Construction, Chicago-Illinois.

Avilés, J., \& Pérez-Rocha, L.E. (2011). Use of global ductility for design of structure-foundation systems. Soil Dynamics and Earthquake Engineering, 31(7), 1018-1026. 
International Journal of Mathematical, Engineering and Management Sciences

Vol. 5, No. 6, 1516-1537, 2020

https://doi.org/10.33889/IJMEMS.2020.5.6.112

Baker, J.W. (2007). Quantitative classification of near-fault ground motions using wavelet analysis. Bulletin of the Seismological Society of America, 97(5), 1486-1501.

Basarir, H., Elchalakani, M., \& Karrech, A. (2019). The prediction of ultimate pure bending moment of concrete-filled steel tubes by adaptive neuro-fuzzy inference system (ANFIS). Neural Computing and Applications, 31(2), 1239-1252.

Bosco, M., \& Rossi, P.P. (2009). Seismic behaviour of eccentrically braced frames. Engineering Structures, 31(3), 664-674.

Bosco, M., Marino, E.M., \& Rossi, P.P. (2015). Modelling of steel link beams of short, intermediate or long length. Engineering Structures, 84, 406-418.

Cai, J., Bu, G., Zhou, J., Zuo, Z., Yang, C., \& Chen, Q. (2016). Modification of ductility reduction factor for strength eccentric structures subjected to pulse-like ground motions. Journal of Earthquake Engineering, 20(1), 12-38.

Chakraborti, A., \& Gupta, V.K. (2005). Scaling of strength reduction factors for degrading elasto-plastic oscillators. Earthquake Engineering \& Structural Dynamics, 34(2), 189-206.

De Luca, F., Iervolino, I., \& Cosenza, E. (2009). Un-scaled, scaled, adjusted and artificial spectral matching accelerograms: displacement-and energy-based assessment. Proceedings of XIII ANIDIS, "L'Ingegneria Sismica in Italia”, Bologna, Italy.

Eskandari, R., Vafaei, D., Vafaei, J., \& Shemshadian, M.E. (2017). Nonlinear static and dynamic behavior of reinforced concrete steel-braced frames. Earthquakes and Structures, 12(2), 191-200.

Fakhraddini, A., Hamed, S., \& Fadaee, M.J. (2019). Peak displacement patterns for the performance-based seismic design of steel eccentrically braced frames. Earthquake Engineering and Engineering Vibration, 18(2), 379-393.

Fanaie, N., \& Ezzatshoar, S. (2014). Studying the seismic behavior of gate braced frames by incremental dynamic analysis (IDA). Journal of Constructional Steel Research, 99, 111-120.

Gerami, M., \& Abdollahzadeh, D. (2013). Local and global effects of forward directivity. Građevinar, 65(11), 971-985.

Habibullah, A. (2016). ETABS-three dimensional analysis of building systems. Manual. Computers and Structures Inc., Berkeley.

Hakim, S., \& Abdul Razak, H. (2013). Adaptive neuro fuzzy inference system (ANFIS) and artificial neural networks (ANNs) for structural damage identification. Structural Engineering Mechanics, 45(6), 779802.

Hancock, J. (2006). The influence of duration and the selection and scaling of accelerograms in engineering design and assessment. Imperial College London (University of London).

Jang, J.S. (1993). ANFIS: adaptive-network-based fuzzy inference system. IEEE Transactions on Systems, Man, and Cybernetics, 23(3), 665-685.

Kalkan, E., \& Kunnath, S.K. (2006). Effects of fling step and forward directivity on seismic response of buildings. Earthquake Spectra, 22(2), 367-390.

Karavasilis, T.L., Bazeos, N., \& Beskos, D. (2008). Seismic response of plane steel MRF with setbacks: estimation of inelastic deformation demands. Journal of Constructional Steel Research, 64(6), 644-654.

Karavasilis, T.L., Bazeos, N., \& Beskos, D.E. (2007). Estimation of seismic drift and ductility demands in planar regular X-braced steel frames. Earthquake Engineering \& Structural Dynamics, 36(15), 22732289. 
International Journal of Mathematical, Engineering and Management Sciences

Vol. 5, No. 6, 1516-1537, 2020

https://doi.org/10.33889/IJMEMS.2020.5.6.112

Kuşyılmaz, A., \& Topkaya, C. (2013). Design overstrength of steel eccentrically braced frames. International Journal of Steel Structures, 13(3), 529-545.

Kuşyllmaz, A., \& Topkaya, C. (2015). Displacement amplification factors for steel eccentrically braced frames. Earthquake Engineering \& Structural Dynamics, 44(2), 167-184.

Lee, L.H., Han, S.W., \& Oh, Y.H. (1999). Determination of ductility factor considering different hysteretic models. Earthquake Engineering \& Structural Dynamics, 28(9), 957-977.

Lu, Y., Hajirasouliha, I., \& Marshall, A.M. (2016). Performance-based seismic design of flexible-base multistorey buildings considering soil-structure interaction. Engineering Structures, 108, 90-103.

Mashayekhi, A., Gerami, M., \& Siahpolo, N. (2019). Assessment of higher modes effects on steel moment resisting structures under near-fault earthquakes with forward directivity effect along strike-parallel and strike-normal components. International Journal of Steel Structures, 19(5), 1543-1559.

McKenna, F. (2011). OpenSees: a framework for earthquake engineering simulation. Computing in Science \& Engineering, 13(4), 58-66.

Nikravesh, M. (2007). Evolution of fuzzy logic: from intelligent systems and computation to human mind. In Forging new frontiers: Fuzzy pioneers I. Springer, Berlin, Heidelberg, pp. 37-53.

No, S. (2005). 2800. Iranian code of practice for seismic resistant design of buildings. Third Revision, Building and Housing Research Center, Tehran.

Özhendekci, D., \& Özhendekci, N. (2008). Effects of the frame geometry on the weight and inelastic behaviour of eccentrically braced chevron steel frames. Journal of Constructional Steel Research, 64(3), 326-343.

Pekelnicky, R., Engineers, S.D., Chris Poland, S.E., \& Engineers, N.D. (2012). ASCE 41-13: Seismic evaluation and retrofit rehabilitation of existing buildings. Proceedings of the SEAOC.

Rossi, P.P., \& Lombardo, A. (2007). Influence of the link overstrength factor on the seismic behaviour of eccentrically braced frames. Journal of Constructional Steel Research, 63(11), 1529-1545.

Siahpolo, N., Gerami, M., \& Vahdani, R. (2016). Inelastic deformation demands of regular steel frames subjected to pulse-like near-fault ground shakings. International Journal of Advanced Structural Engineering, 8(3), 281-296.

Siddique, M.A.A., El Damatty, A.A., \& El Ansary, A.M. (2014). A numerical investigation of overstrength and ductility factors of moment resisting steel frames retrofitted with GFRP plates. Canadian Journal of Civil Engineering, 41(1), 17-31.

Stewart, J.P., Chiou, S.J., Bray, J.D., Graves, R.W., Somerville, P.G., \& Abrahamson, N.A. (2002). Ground motion evaluation procedures for performance-based design. Soil Dynamics and Earthquake Engineering, 22(9-12), 765-772.

Straccia, U. (2013). Foundations of fuzzy logic and semantic web languages. Taylor \& Francis.

Tena-Colunga, A. (2001). Displacement ductility demand spectra for the seismic evaluation of structures. Engineering Structures, 23(10), 1319-1330.

Tzimas, A.S., Karavasilis, T.L., Bazeos, N., \& Beskos, D.E. (2017). Extension of the hybrid force/displacement (HFD) seismic design method to 3D steel moment-resisting frame buildings. Engineering Structures, 147, 486-504.

Veismoradi, S., \& Darvishan, E. (2018). Probabilistic seismic assessment of mega buckling-restrained braced frames under near-fault ground motions. Earthquakes and Structures, 15(5), 487-498. 
International Journal of Mathematical, Engineering and Management Sciences

Vol. 5, No. 6, 1516-1537, 2020

https://doi.org/10.33889/IJMEMS.2020.5.6.112

Xiang, Y., Luo, Y.f., Huang, Q.L., \& Shen, Z.Y. (2018). Vertical ductility demand and residual displacement of roof-type steel structures subjected to vertical earthquake ground motions. Soil Dynamics and Earthquake Engineering, 104, 259-275.

Zhao, Y., \& Tong, G. (2010). Inelastic displacement amplification factor for ductile structures with constant strength reduction factor. Advances in Structural Engineering, 13(1), 15-28. 